\title{
ESTUDO DE USUÁRIOS PARA O DESENVOLVIMENTO DAS ATIVIDADES NAS BIBLIOTECAS DO INSTITUTO FEDERAL DA BAHIA
}

\author{
USER'S STUDIES TO DEVELOP ACTIVITIES IN THE ACADEMIC \\ LIBRARIES AT INSTITUTO FEDERAL DA BAHIA
}

Andréia Santos Ribeiro Silva IFBA

Marcia Ferreira Lima

UFBA

\section{RESUMO}

Neste artigo apresentamos um estudo de usuários desenvolvido nas bibliotecas do Instituto Federal da Bahia com o objetivo de investigar o perfil da comunidade acadêmica e conhecer as suas necessidades de informação além das atividades realizadas nas bibliotecas que contribuam para o desenvolvimento da competência em informação nos usuários. Aponta a importância do estudo de usuários como um canal de comunicação entre a comunidade e a biblioteca, trazendo o modelo de comportamento de busca e uso da informação desenvolvido por Kuhlthau (1991), que representa o processo de construção de sentidos. 0 método se caracteriza como um estudo de caso, que utilizou questionário online com a abordagem de tratamento dos dados quali-quantitativa. Traz, como resultados, que a informação é a condição necessária para o indivíduo adquirir conhecimentos, e a biblioteca é o local apropriado para fomentar programas para o desenvolvimento de habilidades informacionais. Desse modo, precisa ocorrer maior envolvimento por parte dos profissionais da informação no que tange ofertar produtos e serviços que satisfaçam a relação de usuários com as bibliotecas.

Palavras-chave: Estudo de usuários. Competência em informação. Instituto Federal da Bahia.

\section{ABSTRACT}

In this article we present a study of users developed in the libraries of the Instituto Federal da Bahia with the objective of investigating the profile of the academic community and knowing their information needs, besides the activities carried out in the libraries that contribute to the development of information literacy in users. It points out the importance of the study of users as a communication channel between the community and the library, by bringing the information search and use behavior model developed by Kuhlthau (1991), which represents the process of sense construction. The method is characterized as a case study that used online questionnaire with the qualitative-quantitative data treatment approach. It results that information is the necessary condition for the individual to acquire knowledge and the library is the appropriate place to foster programs for the development of informational skills. Thus, there must be greater involvement by information professionals in offering products and services that satisfy the users' relationship with libraries.

Keywords: Study of users. Informational Literacy. Instituto Federal da Bahia. 


\section{INTRODUÇÃO}

Investigar o papel da biblioteca no Instituto Federal da Bahia (IFBA), compreendendo o estímulo ao desenvolvimento da competência em informação, que perpassa por uma formação para o uso das fontes de informação que fomentam a produção de conhecimento e a construção do aprendizado ao longo da vida. Objetivo dessa pesquisa é conhecer as necessidades de informação dos usuários das bibliotecas do Instituto, considerando-se que essas necessidades são contempladas nas atividades fins das bibliotecas. A pesquisa busca, assim, a simetria entre os sistemas e seus usuários, numa tentativa de encontrar uma posição equilibrada e harmoniosa entre usuários e a instituição.

Pensando nas necessidades e possíveis expectativas dos usuários, foi desenvolvida uma pesquisa que pudesse potencializar as ações realizadas pelos bibliotecários, colocando, como foco central a importância do usuário para as unidades informacionais, pois, muitas vezes sem perceber, são desenvolvidas ações para as atividades meio do trabalho dos bibliotecários, esquecendo-se da importância dos usuários nas unidades informacionais. A partir desse estudo, todos os envolvidos no processo terão ciência da necessidade de mudança para atender as demandas de sua comunidade. Outro fator considerado importante foi averiguar a necessidade do usuário em relação aos produtos, serviços e atividades culturais que são desenvolvidas nessas unidades Informacionais. Quanto à metodologia, foi aplicado um questionário via e-mail, por meio do portal da Instituição, tendo como público-alvo a comunidade do IFBA.

A pesquisa traz como resultados a evidência de que bibliotecários trabalhando em conjunto com outros profissionais podem oferecer oportunidades de aprendizagem para a busca e uso da informação nas bibliotecas do Instituto, e a falta dessa cooperação torna a biblioteca um lugar passivo dentro do contexto escolar.

\section{EDUCAÇÃO NA SOCIEDADE DA INFORMAÇÃO: caminhos para a competência em informação}

Para o convívio na Sociedade da Informação o sujeito precisa possuir requisitos educacionais necessários para um aprendizado contínuo, ao longo da vida. Isso requer do indivíduo uma educação continuada, que lhe permita acompanhar as mudanças tecnológicas e, sobretudo, inovar, criando competências sugeridas pela nova economia. 
Para Le Coadic (2004, p. 114), este cenário globalizado, onde o fluxo de informação eletrônica circula constantemente nas redes virtuais, leva o indivíduo a possuir habilidades, atitudes e conhecimentos necessários para aprender a se informar, a informar outros e saber onde encontrar a informação, e essas habilidades não encontraremos em um sistema tradicional de ensino, será preciso um programa onde os estudantes possam aprender para ensinar informação.

Carol Kuhlthau compartilha essa ideia de programas para ensinar a aprender e ensinar habilidades informacionais a alunos, que poderá ocorrer desde as séries iniciais até a universidade. A biblioteca da escola ou da universidade pode ser este espaço fora da educação tradicional e salas de aulas para fomentar programas de competência em informação, essenciais para aprender a aprender, que se aproxima do que Le Coadic (2004, p. 114) considera como "um programa de ensino 'que' levará, [...], a aprender a se informar, aprender a informar, ou seja, aprender a pesquisar e a usar a informação e a construí-la e comunicá-la." Nesse cenário, o conhecimento se constrói a partir da relação do indivíduo com o mundo. A informação é condição necessária para o conhecimento, mas não é condição suficiente, não há conhecimento sem aprendizagem (ALARCÃO, 2011). E passa a ser necessário que entre a informação a ser utilizada e o indivíduo se faça presente a figura do mediador da informação a quem é imprescindível o conhecimento, comprometimento e a responsabilidade. Como asseguram Sanches e Rio (2010, p. 107), “o mero acesso a documentos torna a biblioteca um repositório informacional, eximindo o bibliotecário da participação construtiva de conhecimento."

Sendo assim, a mediação pressupõe atividade de interferência, que perpassa por todo o fazer bibliotecário.

\footnotetext{
Mediação envolve a ação de quem intercede, interfere por alguém por outro; implicando em vários caminhos, opção e escolhas, constatamos que na mediação alguém está entre duas ou mais pessoas, coisas, facilita uma relação, serve de intermediário, sugere algo, sem agir pela pessoa ou lhe impor alguma coisa. (BICHERI, 2008, p. 93).
}

Almeida Júnior (2009) apresenta o que ele desenvolveu como o conceito apropriado para a mediação da informação, que vai além de uma ligação ou ponte entre o usuário da informação e a informação propriamente dita. Para o autor, a mediação da informação está implícita e explícita em todos os fazeres do profissional da informação, e a este conceito tomamos como base para este estudo: 
Toda ação de interferência - realizada pelo profissional da informação - direta ou indireta; consciente ou inconsciente; singular ou plural; individual ou coletiva; que propicia a apropriação de informação que satisfaça, plena ou parcialmente, uma necessidade informacional. (ALMEIDA JÚNIOR, 2009, p. 92).

Para Carvalho Silva e Silva (2012, p. 3), isso significa dizer que a mediação da informação inclui dois fatores fundamentais: a apropriação da informação que é inerente ao processo de produção/disseminação da informação, e a interferência que é inerente aos procedimentos de como a informação será destinada ao usuário.

Quanto a estes conceitos de apropriação da informação e interferência, Vygotsky (1978, p. 32) tem contribuído com a área da Ciência da Informação com questões e reflexões acerca da mediação da informação a partir do seu conceito de Zona de Desenvolvimento Proximal (ZDP), que trata entre as práticas que um aluno já domina em um dado nível e as atividades nas quais ele poderia alcançar intelectualmente com a ajuda de outro.

Podemos visualizar a ZDP no modelo Information Searching Process (ISP), ou o Processo de Busca da Informação, elaborado por Carol Kuhlthau (1991, p. 362), onde um estudante, para realizar a pesquisa, perpassa por diferentes fases até o momento em que ele se depara com o sentimento da incerteza, considerado como o aspecto central do ISP, pois quanto mais informações o estudante recebe para o desenvolvimento da sua pesquisa, maior poderá ser também a incerteza dele; isso não significa que o aumento da incerteza é sintoma de que algo esteja errado, mas de anseios a serem entendidos. Para que essa incerteza seja diminuída e o aluno se aproxime do sentimento de clareza é que Kuhlthau (1991, p. 366) apresentou a Zona de Interferência, considerando o que poderia ocorrer na biblioteca escolar, com a mediação do bibliotecário e do professor com orientações sobre a busca da informação, no momento em que fosse percebida essa incerteza no desenvolvimento da pesquisa, para que o aluno tenha conhecimento da direção que deverá seguir. A mediação e o papel do mediador passam a ser a chave para que o estudante chegue à conclusão das atividades.

Assim, baseado no Modelo do ISP, o aumento da incerteza cria uma zona de intervenção para os mediadores ou intermediários que apoiam os usuários no processo de busca de significados a partir da informação. Baseado, então, no modelo ISP e no princípio de incerteza, Kuhlthau desenvolveu o conceito de zona de intervenção, apoiada na ideia de que o aumento da incerteza determina a necessidade de assistência do aluno. Assim, o conceito de Zona de Intervenção é, portanto, modelado a partir da ZDP de Vygotsky (1978, p. 32), que dá o caminho para o entendimento da intervenção no processo construtivista de uma pessoa. 
Para Kuhlthau (1991, p. 362), a zona de intervenção é a área em que o usuário da informação faz com assistência de outra pessoa o que não pode fazer sozinho. A intervenção nesta zona permite aos indivíduos o cumprimento das suas tarefas. Entretanto, a intervenção fora desta zona é desnecessária e ineficiente e é encarada pelos usuários como intrusiva, o que evoluiu no sentido do conceito de mediação da informação, que desempenha importante função, aproximando centro de informação do usuário.

Baseada nessa mediação necessária ao indivíduo, para que o mesmo possa organizar a informação para constituí-la em conhecimento, é que Alarcão (2011, p. 28) assevera que a nova sociedade exige de todos os indivíduos o permanente aprendizado. 0 aprendizado ao longo da vida, e as escolas precisam preparar seus estudantes para um mundo voltado para a era tecnológica. Como assegura Kuhlthau (1999, p. 9), "não se pode perder de vista que o mundo para o qual está se preparando o estudante é um mundo voltado para a tecnologia." Sendo assim, a escola e a biblioteca escolar precisam preparar esse aluno para vivenciar suas experiências nesta Sociedade da Informação, a qual produz um novo desafio na educação: aprender a aprender (SILVA; NEVES; GOMES, 2013, p. 27).

Werthein (2000) considera a ideia de "aprendizagem" a essência do novo paradigma na Sociedade da Informação. “A noção de 'aprendizagem' passa a ser empregada em vários níveis, sendo o organizacional sua aplicação de maior significado na reestruturação capitalista no novo paradigma." (WERTHEIN, 2000, p. 73).

Essa concepção inicial de aprendizagem apenas organizacional foi logo superada e hoje se percebe que precisamos ter habilidades, atitudes e competências em todos os ramos do nosso fazer, e essas competências podem ser ensinadas às crianças nas séries inicias até a vida adulta. A verdade é que se tivermos nas bibliotecas programas que trabalhem conteúdos de buscas, avaliações e usos das informações, conforme descritas por Alarcão (2011, p. 19), prepararemos os cidadãos para encontrarem as informações necessárias, para decidirem sobre as suas relevâncias e para avaliarem a sua fidedignidade. Sem o saber que lhe permita acessar a informação e ter um pensamento independente e crítico, esse usuário poderá ser manipulado e infoexcluído.

Sendo assim, a escola, na figura do professor, e a biblioteca da escola precisam preparar esse aluno para vivenciar suas experiências nesta Sociedade da Informação, que produz um novo desafio na educação: o aprender a aprender. A biblioteca precisa ofertar variadas fontes de informação e ensinar os alunos a se tornarem autônomos na pesquisa escolar, pois nesta atividade os alunos têm a oportunidade de vivenciar as etapas de um 
programa que desenvolva competências em informação, tais como: possuir a necessidade de informação, acessar conteúdos, usar a informação e transformar em um novo conteúdo.

Assim, o aluno terá independência e levará esse aprendizado para a sua vida cotidiana e profissional. Nesta perspectiva, Kuhlthau assegura que esse aprendizado serve para todas as fases da vida:

0 trabalhador precisa de um alto nível de competência e de habilidade para se adaptar em ambientes em constante mutação. Em segundo lugar, na preparação do estudante para a cidadania é necessário considerar as maneiras pelas quais a tecnologia muda o senso de comunidade do individuo e suscita questões urgentes sobre a sua forma de participação como eleitor informado em uma sociedade democrática. Em terceiro lugar, na preparação de estudantes para a vida cotidiana devem-se considerar as formas pelas quais a tecnologia aumenta a complexidade da vida e desencadeia questões problemáticas sobre como o indivíduo alcança um sentido de si mesmo em relação ao outro e desenvolve criatividade e satisfação pessoal. (KUHLTHAU, 1999, p. 9).

A American Library Association (ALA, 1989) afirma que para uma pessoa ser competente em informação é necessário um conjunto de habilidades que o indivíduo necessita ter para reconhecer quando a informação é necessária, bem como capacidade de avaliar, localizar e usar essa informação na produção de conhecimentos.

Pontes Júnior e Tálamo (2009, p. 82), baseados na Conferência Nacional de Bibliotecas Universitárias ocorrida em Londres, em 1999, apresentaram o modelo que mostra as habilidades e as relações com as competências na busca, recuperação e uso da informação em sete pilares, através do qual o usuário progride na competência com perícia a informação de que ele necessita, ao mesmo tempo praticando suas habilidades adquiridas ao longo do processo.

Lau (2007, p. 13) assevera que as habilidades em informação são fatores-chave para o aprendizado, principalmente no período educacional, pois existe uma relação entre aprendizado ao longo da vida e o uso da informação. Por isso, o autor elaborou diretrizes para criação de Desenvolvimento de Habilidade em Informação (DHI) em bibliotecas, local apropriado para os alunos aprenderem a elaborar estratégias para encontrar a informação, como, ao mesmo tempo, desenvolver o pensamento crítico para selecionar, avaliar e usar essa informação.

A biblioteca poderá ser o espaço destinado a esses programas de ensino, ofertando variadas fontes de informações e ensinando os alunos a se tornarem autônomos na pesquisa escolar, na busca pela informação e na construção de um novo conhecimento. Assim, os alunos terão independência e levarão esse aprendizado para a sua vida cotidiana e 
profissional (SILVA; NEVES; GOMES; 2013, p. 27).

Desse modo, habilitar os alunos a construírem seus próprios sentidos, possuindo habilidades de leitura, escrita e cálculo, adaptando-se às TIC, pois eles precisarão desenvolver habilidades que os ajudem a aprender a partir de uma abundância de informações disponibilizadas pelas redes.

Ferreira (2004) assegura que a educação está relacionada com a difusão do conhecimento via internet, o que tem proporcionado uma formação continuada na sociedade desde o século XVI.

Já na época da Revolução Industrial se desenhava o projeto informático, como resultado histórico de movimentos que abrigavam tecnólogos, filósofos iluministas, lógicos e matemáticos. Diga-se, de passagem, que até Marx advoga, posteriormente, a representação do pensamento dialético através da matemática. 0 código binário, a base dos sistemas de sinais da informática, foi criado por Francis Bacon (século XVI). Descartes, Hobbes e Leibniz desenvolveram várias especulações e tentativas de automatizar o processo de construção do conhecimento e de comunicação. A lógica de Boole e a demonstração de Joseph Fourier (1768-1830) de que os sinais podem ser matematizados deram um passo adiante no sentido da operacionalização dessas prefigurações feitas pelos filósofos. Babagge (1792-1871), um tecnólogo, é quem criará a transposição desses conhecimentos para o mundo prático. Primeiro, para a produção industrial, com a automação através de cartões perfurados dos teares Jacquard (criados em meados do século XVIII), a pedido de Napoleão. Segundo, com os planos de máquinas (de cálculos complexos) visando à confecção de tabelas numéricas para navegação (a pedido do governo inglês). Portanto, podemos falar da informática como um projeto histórico - iluminista - de tecnologia construída por estes e outros filósofos, matemáticos, lógicos e tecnólogos, cujo centro é a automação dos processos de produção social de bens materiais e de bens simbólicos - a linguagem, o conhecimento e a comunicação. (FERREIRA, 2004, p. 231).

Embora a educação pautada no desenvolvimento da Sociedade da Informação seja um fenômeno eminentemente contemporâneo, possui bases que remontam ao início da Idade Moderna e que têm forte diálogo e conflito com os fundamentos históricos e tecnológicos do regime industrial. 0 desenvolvimento das tecnologias digitais e suas contribuições para a educação são buscas incessantes desde a Idade Moderna.

Isso não significa dizer que a sociedade industrial é semelhante à Sociedade da Informação (a sociedade industrial está mais focada na tecnologia como ferramenta de uso restrito para produção e consumo), mas o advento da segunda só pode ter sido constituído a partir de rompimentos na forma de conduzir a produção, acesso, consumo e apropriação de bens materiais e imateriais.

Uma Sociedade da Informação que é mais globalizada, compartilhada e planetária, na medida em que a educação prima pelo desenvolvimento de competências para o uso crítico e dinâmico das tecnologias que estimulem perspectivas de aprendizado de modo dialógico e 
autônomo, deve focalizar um olhar mais amplo para o desenvolvimento humano, e não simplesmente mecânico.

No entanto, é preciso considerar que nem sempre discurso e prática no contexto da Sociedade da Informação são tão próximos e harmoniosos em virtude de haver monopólios e manipulações no controle e uso das tecnologias digitais (como grandes empresas públicas e/ou privadas do capital midiático, industrial e bancário), interferindo negativamente no processo de apropriação crítica da realidade pela população.

O Livro Verde da Sociedade da Informação trata a educação como elemento chave na construção de uma sociedade baseada na informação, no conhecimento e no aprendizado, e vai além quando diz que:

[...] educar em uma sociedade da informação significa muito mais que treinar as pessoas para o uso das tecnologias de informação e comunicação: trata-se de investir na criação de competências suficientemente amplas que lhes permitam ter uma atuação efetiva na produção de bens e serviços, tomar decisões fundamentadas no conhecimento, operar com fluência os novos meios e ferramentas em seu trabalho, bem como aplicar criativamente as novas mídias, seja em usos simples rotineiros, seja em aplicações mais sofisticadas. Trata-se também de formar os indivíduos para 'aprender a aprender', de modo a serem capazes de lidar positivamente com a contínua e acelerada transformação da base tecnológica (TAKAHASHI, 2000, p. 45, grifo do autor).

Pensar a educação na Sociedade da Informação é pensar no papel que as Tecnologias de Informação e Comunicação (TIC) desempenham na construção de uma sociedade que tenha como prioridade a inclusão. A inclusão social pressupõe formação para a cidadania, por isso, as TIC devem ser utilizadas para a democratização, para a transparência política e para incentivar a mobilização dos cidadãos. Nesse sentido, as TIC devem ser utilizadas para integrar a escola e a comunidade (TAKAHASHI, 2000). Formar cidadãos significa capacitar as pessoas para a tomada de decisão.

Para se atingirem avanços efetivos e permanentes e educar a população para a sociedade do conhecimento, torna-se necessário um conjunto amplo de ações consistentes, complementares e contínuas, voltadas para a estrutura formal de ensino e para a comunidade em geral. Ao lado da modernização e do aperfeiçoamento do ensino de ciências nas escolas, tornam-se prioritários a elevação da qualidade e do interesse da cobertura dos meios de comunicação aos assuntos de Ciência, Tecnologia e Inovação; o desenvolvimento de redes de educação à distância e a ampliação e o aperfeiçoamento de bibliotecas virtuais; o treinamento de professores e produção de conteúdos para internet relacionados à divulgação científica; o fortalecimento e a ampliação de museus e exposições de Ciência e Tecnologia (BRASIL, 2002, p. 69).

Vieira (2005) justifica as mudanças ocorridas na sociedade como sendo desejáveis 
para uma Sociedade da Informação para todos:

[...] as mais significativas desde a Revolução Industrial, [e] são de longo alcance e globais. Não se trata meramente de mudanças tecnológicas, pois elas afectarão todas as pessoas, em todos os locais. Aproximando comunidades, rurais e urbanas, criando riqueza e partilhando conhecimentos, têm um enorme potencial para enriquecer a vida de todas as pessoas (COMISSÃO EUROPEIA, 1999, p. 2 apud VIEIRA, 2005, p. 87).

Vieira (2005, p. 82) relata ainda a diferença que existe nos documentos europeus sobre o que seria o significado da máxima da educação na Sociedade da Informação: "aprender ao longo da vida". Conforme discutido pela autora em alguns documentos, podemos concluir que os relatórios traduziram esses aprendizados como competências digitais, trabalhar em equipe para resolver problemas, saber usar a informação e outras competências informacionais necessárias aos indivíduos.

Caregnato (2000, p. 50) afirma que esse termo designa as habilidades que o indivíduo precisa ter no uso das bibliotecas, no percurso dos estudos, a cognição necessária para a manipulação da informação, e outros. Lau (2007) apresenta diferentes conceitos de habilidades em informação de diferentes autores e associações. 0 autor cita American Association of School Librarians (AASL), que se refere a habilidades em informação, como as "habilidades para acessar e usar a informação", e afirma ainda que "estudantes com habilidades em informação acessam a informação de forma efetiva e eficientemente, avaliam a informação de maneira crítica e competente e utilizam de maneira criativa e precisa." (LAU, 2007, p. 7).

Para a nova sociedade baseada no conhecimento e uso da informação e das tecnologias digitais, o aprendizado ao longo da vida e as habilidades informacionais começam a dar espaço a outro termo designado de competência em informação, que não se limita ao conhecimento do uso das fontes de informação e de bibliotecas, mas diz respeito, sobretudo, em entender, avaliar criticamente e usar o autoaprendizado e a tecnologia de forma ética. Coelho (2008, p. 39) assevera que a origem do termo competência em informação está no próprio contexto da Sociedade da Informação, em decorrência do aumento do volume de informações, do incremento das tecnologias, como também da síndrome da fadiga da informação.

O conceito de competência informacional, associado com aprendizagem ao longo da vida, foi enfatizado, inicialmente em todos os setores da educação, ampliando-se o interesse para os profissionais da informação e preconizando-se a necessidade de educar todas as pessoas para viverem e trabalharem na sociedade da informação (AMERICAN LIBRARY ASSOCIATION, 1989, p. 1). 
A competência em informação, termo que utilizamos nesse estudo, constitui uma capacidade essencial aos cidadãos para se adaptarem à nova realidade da sociedade informacional, implicando que as pessoas tenham capacidade de entender suas necessidades de informação e de localizar, selecionar e interpretar informações, utilizando-as de forma crítica e responsável.

Para que estes objetivos possam ser alcançados em uma biblioteca escolar, e que a mesma possa construir sentidos na vida de um aluno, será necessária uma reestruturação na aprendizagem baseada em questionamentos, “onde o estudante está envolvido ativamente no processo de construção de significados.” (KUHLTHAU, 1999, p. 10). Nesse cenário, o bibliotecário deverá desempenhar um papel importante na criação de uma biblioteca escolar como centro de questionamentos, tornando-se o mediador da informação.

\section{DESENVOLVIMENTO DE COMPETÊNCIAS EM INFORMAÇÃO A PARTIR DA BIBLIOTECA NA ESCOLA}

0 termo competência em informação culminou com a publicação, em 1989, do relatório final do Presidential Committee on Information Literacy da American Library Association (ALA), designando um conjunto de habilidades e conhecimentos necessários a um indivíduo para conviver na sociedade atual.

O mais importante dos documentos sobre competência em informação, e que diz respeito à biblioteca escolar, é o Information Power, de 1998, o qual indica competências a serem desenvolvidas na escola, além das funções desse tipo de biblioteca e do profissional que nela atua.

Quadro 1 - Normas de competência em informação.

\begin{tabular}{|c|c|c|}
\hline \multirow{3}{*}{ 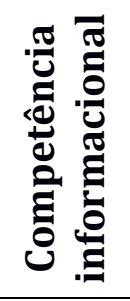 } & 1. & $\begin{array}{l}0 \text { aluno que tem competência informacional acessa a informação de forma } \\
\text { eficiente e efetiva; }\end{array}$ \\
\hline & 2. & $\begin{array}{l}0 \text { aluno que tem competência informacional avalia a informação de forma } \\
\text { critica e competente; }\end{array}$ \\
\hline & 3. & $\begin{array}{l}0 \text { aluno que tem competência informacional usa a informação com precisão e } \\
\text { criatividade; }\end{array}$ \\
\hline \multirow{2}{*}{ 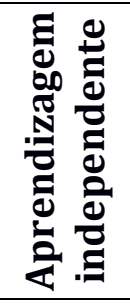 } & 4. & $\begin{array}{l}\text { O aluno que tem capacidade de aprender com independência possui } \\
\text { competência informacional e busca informação relacionada com os seus } \\
\text { interesses pessoais com persistência; }\end{array}$ \\
\hline & 5. & $\begin{array}{l}\text { O aluno que tem capacidade de aprender com independência possui } \\
\text { competência informacional e aprecia literatura e outras formas criativas de } \\
\text { expressão da informação; }\end{array}$ \\
\hline
\end{tabular}




\begin{tabular}{|l|l|l|}
\hline & 6. & $\begin{array}{l}\text { O aluno que tem capacidade de aprender com independência possui } \\
\text { competência informacional e se esforça para obter excelência na busca de } \\
\text { informação e de geração de conhecimentos. }\end{array}$ \\
\hline \multirow{2}{*}{\begin{tabular}{l} 
O \\
\cline { 2 - 3 }
\end{tabular}} & $\begin{array}{l}\text { 0 aluno que contribui positivamente para a comunidade de aprendizagem e } \\
\text { para a sociedade tem competência informacional e pratica o comportamento } \\
\text { ético em relação à informação e à tecnologia da informação; }\end{array}$ \\
\cline { 2 - 3 } & 8. & $\begin{array}{l}\text { O aluno que contribui positivamente para a comunidade de aprendizagem e } \\
\text { para a sociedade tem competência informacional e pratica o comportamento } \\
\text { ético em relação à informação e à tecnologia da informação; }\end{array}$ \\
\cline { 2 - 3 } & 9. & $\begin{array}{l}\text { O aluno que contribui positivamente para a comunidade de aprendizagem e } \\
\text { para a sociedade informacional tem competência informacional e participa } \\
\text { efetivamente de grupos, a fim de buscar e gerar informação. }\end{array}$ \\
\hline
\end{tabular}

Fonte: AASL, adaptado de Campelo (2006).

A competência informacional concentra-se em dar ao aluno ou ao trabalhador ferramentas que lhes proporcionarão aprendizagem continuada para fazer pesquisa independente, conduzida e direcionada pelos seus próprios entendimentos, para aprender e, por conseguinte, contribuir de forma positiva com a sociedade (COELHO, 2008, p. 64).

A expressão competência informacional originou-se em meio ao surgimento da Sociedade da Informação que se caracterizou pelo rápido crescimento das informações disponibilizadas e as mudanças ocasionadas pelas tecnologias usadas no ciclo informacional. A noção de tecnologia da informação que perpassa no conceito de competência em informação é considerada por Campelo (2009) como uma consequência natural do conceito de Sociedade da Informação.

Na atual sociedade, uma das principais tarefas da biblioteca escolar é proporcionar o uso de fontes de informação e transformação dessas informações em conhecimentos, especialmente dos estudantes em fase de aprendizagem.

O conceito de Sociedade da Informação pressupõe que exista uma aprendizagem ao longo da vida e o desenvolvimento de habilidades para o uso da informação, de acordo com o contexto social no qual o indivíduo está inserido. Faz-se necessário, portanto, conhecimento sobre o acesso à informação e seu uso crítico e eficaz.

Campelo (2003, p. 30), ao citar uma publicação de 1998, intitulada Association for Educational Communications and Technology Information power: building partnerships for leaning, da American Association of School Librarians (AASL), sintetiza o contexto que justifica a exigência inevitável da competência em informação na Sociedade da Informação como o espaço mais abrangente por onde trafega o movimento da competência em informação. É o mundo 'alterado pela rápida disponibilização de uma abrangência de informação, em uma variedade de formatos'. 
É um ambiente tão diferente e mutante que exige novas habilidades para nele se sobreviver. Espaço problemático e interconectado, que vai demandar que as crianças desenvolvam capacidades que lhes permitam aprender a reconhecer e lidar com visões de mundo diferentes das suas (CAMPELO, 2003, p. 33).

Nesta Sociedade da Informação, uma das tarefas importantes da biblioteca escolar é proporcionar o uso de fontes de informação e transformação dessas informações em conhecimento, especialmente dos estudantes em fase de aprendizagem, sendo que professores e bibliotecários precisam formar experiência para desenvolver a competência em informação no estudante.

Nessa perspectiva, as escolas precisam preparar seus estudantes para um mundo voltado para a era tecnológica. Como assegura Kuhlthau (1999, p. 9), "não se pode perder de vista que o mundo para o qual está se preparando o estudante é um mundo voltado para a tecnologia."

O trabalhador precisa de um alto nível de competência e de habilidade para se adaptar em ambientes em constante mutação. Em segundo lugar, na preparação do estudante para a cidadania é necessário considerar as maneiras pelas quais a tecnologia muda o senso de comunidade do indivíduo e suscita questões urgentes sobre a sua forma de participação como eleitor informado em uma sociedade democrática. Em terceiro lugar, na preparação de estudantes para a vida cotidiana deve-se considerar as formas pelas quais a tecnologia aumenta a complexidade da vida e desencadeia questões problemáticas sobre como o indivíduo alcança um sentido de si mesmo em relação ao outro e desenvolve criatividade e satisfação pessoal (KUHLTHAU, 1999, p. 9).

Desse modo, a competência em informação habilita o aluno a construir seus próprios sentidos, possuindo habilidades de leitura, escrita e cálculo, adaptando-se às TIC, pois ele precisa desenvolver habilidades que o ajudem a aprender a partir de uma abundância de informações.

Para que este objetivo possa ser alcançado em uma biblioteca escolar, e que a mesma possa construir sentidos na vida de um aluno, será necessária uma reestruturação na aprendizagem baseada em questionamentos, "onde o estudante estará envolvido ativamente no processo de construção de significados." (KUHLTHAU, 1999, p. 10). Nesse cenário, o bibliotecário deverá desempenhar um papel importante na criação de uma biblioteca escolar como centro de questionamentos.

Pensando nesse sentido é que a bibliotecária norte-americana Kuhlthau (1991) pesquisou e desenvolveu o modelo ISP, que é uma abordagem alternativa ao modelo do comportamento informacional que descreve pessoas que procuram informação para realizar 
uma determinada tarefa dentro de um determinado período de tempo, como o caso da pesquisa na biblioteca escolar. Segundo Campelo (2010, p. 27), a aprendizagem nesse processo acontece pela construção ativa de novas ideias ligadas aos processos cognitivos de cada aluno. Para Kuhlthau (2010, p. 24), “a pesquisa que utiliza a abordagem baseada em processos combina a aprendizagem de conteúdos com a de habilidades de uso da informação, necessários para lidar com problemas reais em contextos do mundo real na era da informação."

Nesse sentido, a biblioteca escolar deve assegurar que o aluno tenha uma aprendizagem baseada em processos para a atividade da pesquisa escolar, que deverá "estar centrada na construção do conhecimento do usuário." (CARVALHO SILVA; SILVA, 2012, p. 17).

Demo (1996) considera que a educação pela pesquisa ocorre em dois momentos: o primeiro é quando o professor aplica a pesquisa no seu cotidiano e faz dele uso constante dessa atividade, servindo, assim, de exemplo para os seus alunos; e o segundo, quando o aluno apreende os passos da pesquisa e passa a ser companheiro de trabalho desse professor. Para isso, é necessário competências do professor, orientador da pesquisa escolar; do bibliotecário, responsável pelo ensinamento das fontes de informação e orientação para a pesquisa na biblioteca escolar; e do aluno, a quem se destina a educação pela pesquisa.

Segundo Carvalho Silva e Silva (2012, p. 19, adaptado de DEMO, 1996), para incentivar o hábito de pesquisa, a biblioteca da escola poderá mediar atividades que possam ser aplicadas, tais como: elaborar guias para elaboração de artigos, projetos, monografias, normalização e outros; promover a divulgação permanente de eventos, revistas e produção dos docentes; estimular a atividade de pesquisa como a produção do conhecimento; elaborar eventos, palestras e outras atividades que abordem o cotidiano da comunidade.

Kuhlthau (2010, p. 24) completa dizendo que:

desenvolver habilidades de pesquisa como um processo de busca da informação. Sendo necessário para muitos indivíduos na Sociedade da Informação possuir a habilidade de identificar necessidades de informação, localizar informações apropriadas e utilizá-las para aprender, tomar decisões e resolver problemas é necessário a qualquer pessoa.

O modelo do processo de busca da informação desenvolvido por Kuhlthau para a pesquisa ocorre em seis estágios (iniciação, seleção, exploração, formulação, coleta, apresentação) e deverá ser aplicado em uma biblioteca tanto escolar quanto em outras fases de aprendizagem. Os estágios do processo são denominados de acordo com a tarefa a ser 
realizada e os sentimentos que envolvem cada etapa. A avaliação ao final do processo tornase necessária para examinar o progresso que foi obtido pelo aluno.

$\mathrm{Na}$ fase inicial do processo de busca da informação, o aluno sente-se confuso e inseguro, pois ainda não possui domínio do conteúdo abordado para a pesquisa. Como assegura Campelo (2010, p. 27), a biblioteca escolar nesta fase pode ser o espaço para o desenvolvimento dessa atividade, e o bibliotecário da escola pode ser o parceiro nesse processo junto ao professor.

Figura 1 - Processo de busca da informação.

\begin{tabular}{|c|c|c|c|c|c|c|}
\hline \multicolumn{7}{|c|}{ Processo de Busca da Informação } \\
\hline $\begin{array}{l}\text { Estágios } \\
\text { Sentimentos } \\
\text { (afetivo) }\end{array}$ & $\begin{array}{l}\text { Iniciação } \\
\text { incerteza }\end{array}$ & $\begin{array}{c}\text { Seleção } \\
\text { otimismo }\end{array}$ & $\begin{array}{l}\text { Exploração } \\
\text { confusão } \\
\text { frustração } \\
\text { dúvida }\end{array}$ & $\begin{array}{l}\text { Formulação } \\
\text { clareza }\end{array}$ & $\begin{array}{l}\text { Coleta } \\
\text { senso de } \\
\text { direção/ } \\
\text { confiança }\end{array}$ & $\begin{array}{l}\text { Apresentação } \\
\text { satisfação ou } \\
\text { desapontamento }\end{array}$ \\
\hline \multirow{2}{*}{$\begin{array}{l}\text { Pensamentos } \\
\text { (cognitivo) }\end{array}$} & & . & 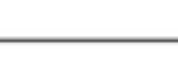 & $\longrightarrow$ focado & & \\
\hline & & & & & \multicolumn{2}{|c|}{ crescimento do interesse } \\
\hline $\begin{array}{l}\text { Açōes } \\
\text { (físico) }\end{array}$ & \multicolumn{2}{|c|}{ buscando inf. relevante } & & & \multicolumn{2}{|c|}{$\rightarrow$ buscando inf. pertinente } \\
\hline
\end{tabular}

Fonte: Adaptado de Kuhlthau (1991).

Uma boa biblioteca possuindo coleções selecionadas que atendam aos perfis do seu público, sendo organizada de forma a permitir que os alunos encontrem os materiais que procuram, também pode auxiliar os alunos no processo de busca da informação, fazendo com que, durante a fase de seleção, o aluno possa diminuir a sua incerteza e começar a se familiarizar com o que está pesquisando.

Possuindo um pouco de certeza e sensação de otimismo, o estudante começa a fase de exploração dos materiais necessários à sua produção, nesta fase ele será capaz de coletar informações que o ajudem a formular o foco da sua pesquisa, mais uma vez uma biblioteca bem organizada, com um bibliotecário auxiliando o processo de busca da informação, poderá fazer com que esse aluno encontre o foco da sua pesquisa de forma mais rápida e com qualidade de busca. Nesse momento, o estudante precisa ter conhecimento sobre a literatura daquilo que ele estabeleceu como foco para o seu trabalho. Em seguida, o aluno percebe a sua perspectiva em relação ao que ele está pesquisando, tomando consciência de suas necessidades. Na fase da coleta, o aluno deverá reunir todos os materiais que ele selecionou, 
fazendo conexões entre as informações e produzindo o texto que será apresentado para os seus colegas e professores.

O processo de produção do conhecimento é um meio adequado para levar os alunos a trabalhar com autonomia, usando variadas fontes de informação. Essa perspectiva está centrada no processo de aprendizagem construtivista, que vem realizando estudos para ajudar a entender como as pessoas aprendem pela busca e uso de informações.

Segundo este referencial, o conhecimento não é uma representação da realidade, mas um mapeamento das ações e operações conceituais que provaram ser viáveis na experiência do indivíduo. Portanto, a aprendizagem é um resultado adaptativo que tem natureza social, histórica e cultural. [...] o processo de desenvolvimento é otimizado pelo aprendizado e que a presença ou a colaboração de outra pessoa mais capaz conduz este processo, o referencial sócio construtivista situa a educação e a escola como tendo um papel essencial na promoção do desenvolvimento dos indivíduos, e o professor, como planejador, observador, promotor e desafiador do desenvolvimento dos mesmos. (BOIKO; ZAMBERLAN, 2001, p. 51).

Documentos elaborados em reuniões que abordavam a competência em informação, como as de Praga, em 2003, e Alexandria, em 2005, sugerem a formação do usuário da informação, declarando que a competência em informação é um pré-requisito básico para uma participação efetiva do indivíduo na Sociedade da Informação, tendo como conexão a aprendizagem permanente.

A formação de usuários no processo de busca e uso da informação tem como sentido contar com um usuário formado que tenha competências suficientes para entender o que é a informação e o seu processo de produção, organização, recuperação uso e transformação para uma nova informação e conhecimento em função da sua vida pessoal e social.

Muitos documentos debatidos sobre o tema abordaram diretrizes para a formação de usuários da informação, tais como: a informação e sua importância; orientação e instrução da biblioteca; uso e produção da informação. Nesse sentido, o que as pessoas necessitam não é simplesmente saber usar a biblioteca, e sim dominar as competências para informar-se e usar a informação disponível em qualquer suporte e lugar, o que implica conhecer as fontes e aplicar os procedimentos adequados para obter informação.

\section{METODOLOGIA}

Como o objeto empírico desta investigação são as bibliotecas de uma instituição, a pesquisa se apoiou no método de estudo de caso, que, segundo Goldenberg (2011, p. 33), não 
é uma técnica específica, mas sim uma análise holística, a mais completa possível, que considera a unidade social estudada como um todo. Sendo o principal objetivo do estudo de caso compreender a instituição ou a comunidade em seus próprios termos.

Segundo Bell (2008, p. 17), o método de estudo de caso pode ser apropriado para pesquisas em Ciências Sociais "[...] porque possibilita que um determinado aspecto de um problema seja estudado com alguma profundidade." 0 mesmo autor ressalta, ainda, que todas as organizações e indivíduos possuem suas características comuns e específicas, por isso um estudo de caso nessas organizações visa identificar os vários processos interativos que influenciam a maneira como as organizações funcionam. Para completar, o estudo de caso tem sido feito sobre decisões, programas, processos de implantação e mudança organizacional (YIN, 2010).

No primeiro momento desta investigação foi realizado um levantamento bibliográfico sobre o tema biblioteca escolar e estudo de usuários da informação: conceitos e competências apontadas pela literatura, além do histórico do IFBA, uma instituição centenária. Essa etapa objetivou uma aproximação teórica com o tema da pesquisa para elaboração do instrumento de coleta de dados.

A abordagem de tratamento dos dados nesse estudo é qualitativa e quantitativa (quali-quanti), pois a análise apresenta dados do discurso da pesquisa qualitativa e procedimentos estatísticos com validade científica da pesquisa quantitativa (BARROS; LEHFELD, 2010), em nível descritivo, pois, segundo Gil (2010), a pesquisa descritiva tem como objetivo a descrição das características de determinada população, incluindo as características de um grupo, utilizando-se da técnica de aplicação de questionários. Os questionários foram aplicados aos discentes, docentes e técnico-administrativos do IFBA, via e-mail e por meio do portal da Instituição. Segundo Cunha (1982, p. 8), “[...] O questionário é autoadministrável podendo ser empregado na ausência do pesquisador."

\section{RESULTADOS E DISCUSSÕES}

Para o desenvolvimento da pesquisa, além de armazenar, classificar e codificar as observações feitas e os dados obtidos, o mais importante desta fase da pesquisa é analisá-los. Para Barros e Lehfeld (2010, p. 87), analisar os dados significa buscar o sentido mais explicativo dos resultados da pesquisa.

Conforme explicado anteriormente, aplicamos os instrumentos para coleta de dados, 
os questionários eletrônicos disponibilizados na página web do Sistema de Bibliotecas e encaminhado por e-mail na lista oficial do Instituto, por um período de três meses (setembro/ outubro/novembro/ 2017) para discentes e servidores da instituição.

Obteve-se um retorno de 229 respostas. Sendo que 151 dos respondentes eram alunos, 22 respostas de técnico-administrativos e 56 respostas de professores dos seguintes campi, conforme gráfico a seguir:

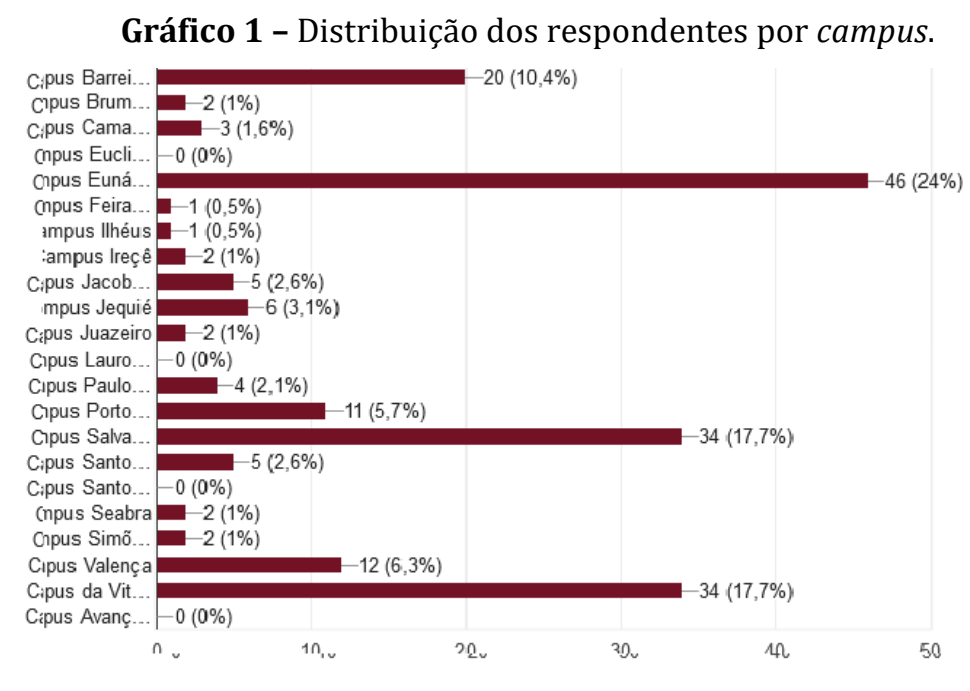

Fonte: Dados da pesquisa.

Os cursos que mais participaram da pesquisa foram: Informática, Edificações, Eletrônica, da modalidade Integrado, seguido dos cursos da graduação, Engenharia Elétrica, Engenharia Civil, e Meio Ambiente, conforme observado nas respostas abertas.

Sobre a frequência desses usuários nos espaços das bibliotecas, percebe-se que diariamente frequentam a biblioteca, sendo 32,8\% dos entrevistados confirmam essa frequência diária e outros $45 \%$ frequentam até três vezes na semana. A frequência diária na biblioteca é quase que exclusivamente para empréstimos e devoluções de obras, seguida da consulta e leitura nos ambientes individuais. Corroborando isso, percebe-se que os usuários só estão em busca de livros físicos, em consonância com gráfico 2: 
Gráfico 2 - Serviços mais utilizados.

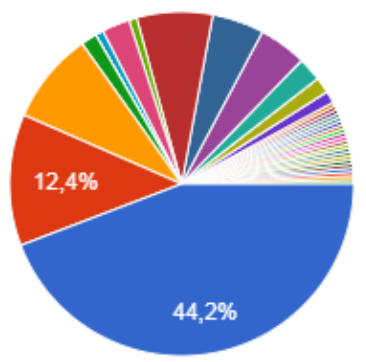

Empréstimos de livros, Devoluções

Consulta local/ Estudo individual e.

Estudo em Grupo

Acesso a Internet;

Pesquisa em base de dados e catál...

Auxilio do Bibliotecário/ Responder

Solicitar Informações;

Utilizar recursos multimídia;

Fonte: Dados da pesquisa.

A reforma do ensino, pautada na Escola Nova idealizada por Anísio Teixeira, legitimou a biblioteca escolar, construindo uma valorização educativa e de estímulo ao processo de ensino-aprendizagem. Nesse período ocorre ao discurso da importância da composição do acervo e da participação direta dos usuários discentes e dos pais na construção da biblioteca escolar, por meio de ações pedagógicas. Além do acervo, contendo suportes físicos e virtuais, a biblioteca deve disponibilizar serviços de aprendizagem e o uso efetivo das tecnologias digitais.

A biblioteca deve exercer as funções de incentivo à leitura dos estudantes, aprimorar a produção e uso da informação em diversos suportes e meios de comunicação, apoiar as atividades integradas ao currículo da escola (UNESCO, 1999).

Desse modo, as bibliotecas do IFBA precisam criar maneiras de fidelizar esses usuários em várias atividades, pois percebe-se que os usuários subutilizam a unidade de informação por falta de conhecimento dos recursos disponíveis e das ações desenvolvidas pela biblioteca. Os usuários deixam de conhecer outras formas de consulta e leitura, como, por exemplo, os livros eletrônicos disponibilizados pela Instituição, de acordo com os gráficos que se seguem:

Gráfico 3 - Fontes de informações mais consultadas.

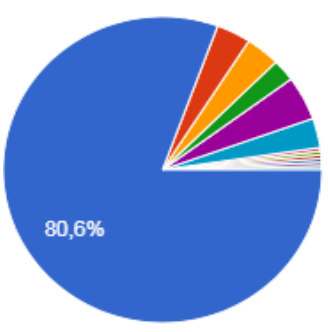

Livros

Periódicos/Revistas

Teses e Dissertações

- Bases de Dados/Portal da CAPES

Livros Eletrônicos

Bases de Consulta da ABNT

Repositórios Institucionais

internet

Fonte: Dados da pesquisa. 
Esse dado é reforçado quando a maioria dos respondentes afirmam que o conteúdo a ser pesquisado possui um exemplar na biblioteca disponível para o empréstimo:

Gráfico 4 - Disponibilidade de exemplares do livro.
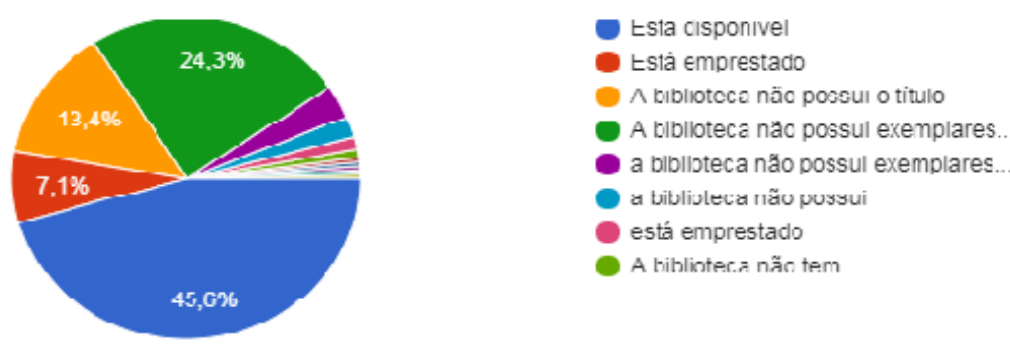

Fonte: Dados da pesquisa.

Carvalho Silva e Silva (2012) entendem que a coleção da biblioteca não pode ser realizada de maneira aleatória, a biblioteca precisa fornecer diversos suportes de busca de conteúdo.

O acervo precisa ser formado e desenvolvido com critérios levando-se em conta o Projeto Político Pedagógico da escola, em função das propostas curriculares de cada área oferecendo materiais de consulta, acesso à internet, para garantir que os alunos utilizem esse tipo de recurso, livros para empréstimo domiciliar e periódicos. (CARVALHO SILVA; SILVA, 2012, p. 12).

Desse modo, o aluno terá uma vasta gama de possibilidades de realizar uma pesquisa, um trabalho ou até mesmo de uma leitura. Mas, na prática, a realidade apresenta uma distorção, pois, mesmo com outras ferramentas de busca, o aluno ainda desconhece os instrumentos que estão à sua disposição.

Gráfico 5 - Utilização das bases de livros eletrônicos.

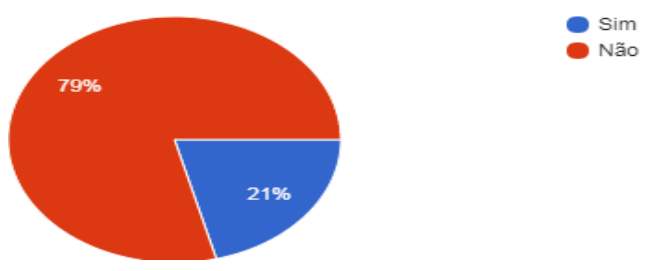

Fonte: Dados da pesquisa.

Os 79\% dos respondentes desconhecem as bases de livros eletrônicos assinados pela Instituição, sendo isso proveniente da falta de treinamentos ou divulgação aos usuários dos 
sistemas vigentes. Como um ponto está implicitamente ligado a outro, provavelmente seja um dos motivos que geram a insatisfação do usuário, frente à falta de livros físicos insuficientes para empréstimos in loco.

A biblioteca tem a tarefa de coletar e disponibilizar materiais informacionais nos diversos formatos, tanto em papel quanto em audiovisuais e meios eletrônicos, como a internet. Dessa maneira, a coleção da biblioteca não é um conjunto de materiais reunidos aleatoriamente e sem nenhum propósito (CAMPELO, 2009).

Gráfico 6 - Satisfação do usuário em relação ao acervo.

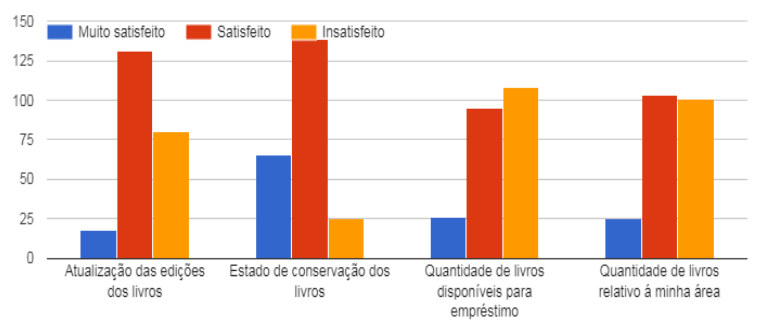

Fonte: Dados da pesquisa.

Como percebe-se no gráfico 6, quando os usuários não encontram o livro físico específico que procuram para a pesquisa, eles afirmaram que preferem buscar a informação em outros recursos, como o Google, deixando de realizar as suas buscas nos livros acadêmicos digitais ou desistindo da busca. Apenas 9,6\% dos usuários que responderam ao questionário informaram que buscam o bibliotecário do campus ou de outra unidade para sanar dúvidas e orientá-los quanto a uma nova estratégia de busca. Percebe-se, também, uma deturpação nesse gráfico quanto à insatisfação apresentada na quantidade de livros disponíveis para empréstimos na biblioteca, pois no gráfico 4 , o usuário considera-se satisfeito com a disponibilidade dos livros para empréstimos.

Gráfico 7 - Estratégias para a busca da informação.

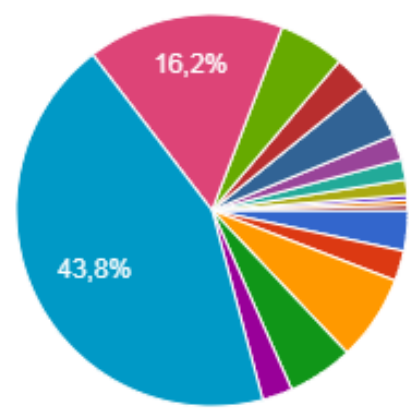

Desiste do livro/periódico

Procura em outra biblioteca

Pede ajuda ao bibliotecário

Compra o livro

Tira Xerox

Busca no Google

Busca no Google Acadêmico

Busca em bases de livros eletrônicos

Fonte: Dados da pesquisa. 
O gráfico 7 deixa claro que não existe envolvimento dos usuários em relação à busca pela informação, necessitando do envolvimento do bibliotecário para orientar essa busca. A pesquisa é uma didática que pressupõe o envolvimento ativo do usuário na construção de seu conhecimento. Como estratégia didática, deve ser, portanto, orientada e mediada. Conforme destacou Campelo (2009, p. 42), a pesquisa orientada é definida como a intervenção do professor e do bibliotecário, cuidadosamente planejada e supervisionada para orientar os usuários na exploração de temas.

No âmbito da biblioteca, a teoria aponta que o bibliotecário que atua na escola deve ser ativo, e a mediação da informação deve fazer parte de todos os fazeres desse profissional. 0 fato é que bibliotecários precisam participar do processo de aprendizagem, trabalhando em colaboração com o professor, e eliminar o que Campelo (2009) chamou de "característica típica do bibliotecário: a preferência por trabalhar isolado."

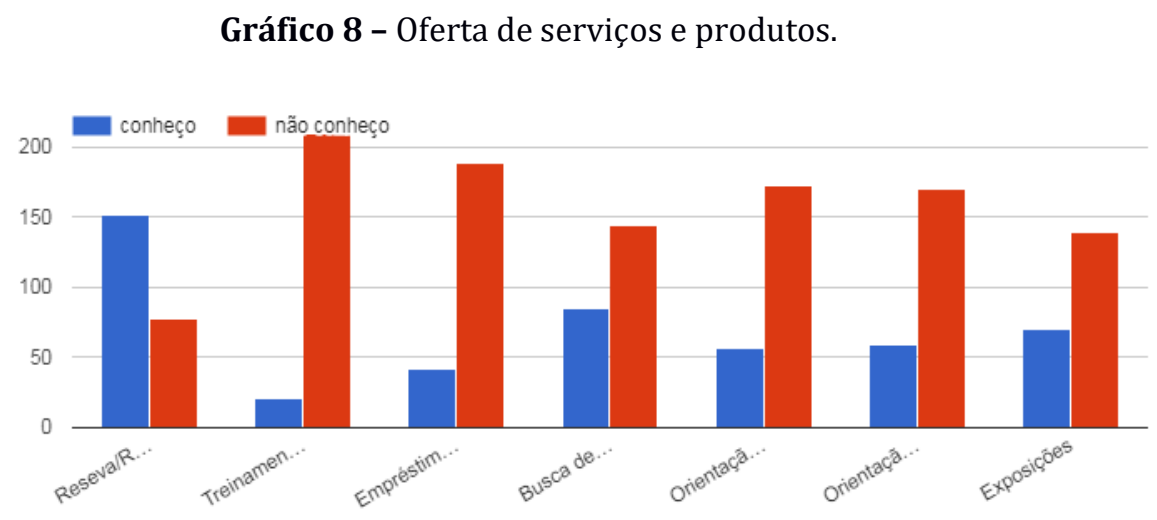

Fonte: Dados da pesquisa.

O envolvimento do bibliotecário na orientação aos usuários para a busca da informação poderia refletir nas respostas do gráfico 8. Nesse caso específico, os usuários conhecem apenas o serviço básico da biblioteca: reserva/renovação/empréstimo.

O trabalho em colaboração do bibliotecário e do docente poderá refletir em uma boa orientação do que seja a biblioteca dentro da instituição de ensino. Os usuários precisam conhecer a oferta de serviços e produtos disponíveis na biblioteca para que possam ter a empatia de sugerir, por exemplo, a aquisição de livros paradidáticos, o que não ocorre atualmente em muitos campi, conforme a fala de muitos alunos que responderam ao questionário. Mesmo com todas as dificuldades apresentadas nessa pesquisa, os usuários sentem que os serviços oferecidos e as atividades desempenhadas na biblioteca estão 
compatíveis com as suas necessidades, visto que a necessidade de informação desses usuários tem se resumido à busca pela informação do livro impresso.

A mediação da informação está ligada a todo o fazer do profissional da informação, e é um efetivo instrumento para reflexões e estudos no campo da Ciência da Informação. Sendo assim, significa dizer que a mediação da informação é uma atividade que está inserida no cotidiano, é construída por meio do diálogo com o ser e com vistas à satisfação de determinadas necessidades informacionais (CARVALHO SILVA; SILVA, 2012, p. 4).

Partindo da premissa que a mediação permeia por todas as atividades do bibliotecário, é natural que esse profissional as desenvolva naturalmente, contribuindo com a formação do aluno. Provavelmente este é o motivo para que $72,5 \%$ dos participantes informaram estarem satisfeitos com os serviços da sua biblioteca.

Gráfico 9 - Grau de satisfação com os serviços oferecidos na biblioteca.

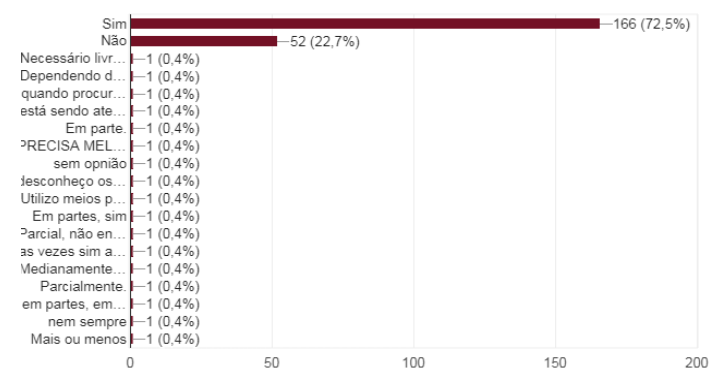

Fonte: Dados da pesquisa.

Mesmo desconhecendo alguns serviços da biblioteca, 72,5\% dos usuários sentem-se satisfeitos com os serviços que conhecem, nesse caso empréstimo/renovação. Para atuar na Sociedade da Informação, o indivíduo deve reconhecer quando precisa de informação e deve possuir habilidades para saber localizar, avaliar e usar efetivamente a informação, assim como habilidades para utilizar a biblioteca (AMERICAN LIBRARY ASSOCIATION, 1989).

Conforme Bagno (1998), ensinar a aprender também é criar possibilidades para que o usuário chegue sozinho às fontes de conhecimento que estão à sua disposição. Ensinar a aprender, então, não é apenas mostrar os caminhos, mas também orientar o usuário para que desenvolva um olhar crítico que lhe permita reconhecer as trilhas que conduzem às verdadeiras fontes de informação e conhecimento.

A transição da busca e uso da informação do meio físico (biblioteca) para o meio eletrônico (internet) já ocorre, por ser este um dos novos hábitos de pesquisa na 
contemporaneidade, na qual a internet desempenha grandes funções, tais como: pesquisar, comunicar e publicar. Possuir a habilidade para a busca de informação é tão necessário quanto selecionar e avaliar essa informação na web (VIEIRA, 2005). Desse modo, ter acesso a uma boa rede de internet é fundamental nos dias atuais, principalmente no espaço da biblioteca, onde muitas atividades deixaram de ser no meio físico, principalmente os empréstimos, consultas e renovações realizadas constantemente pelos usuários. Assim, procuramos saber como é a rede wireless do campus no gráfico a seguir:

Gráfico 10 - Satisfação com a rede wireless na biblioteca.

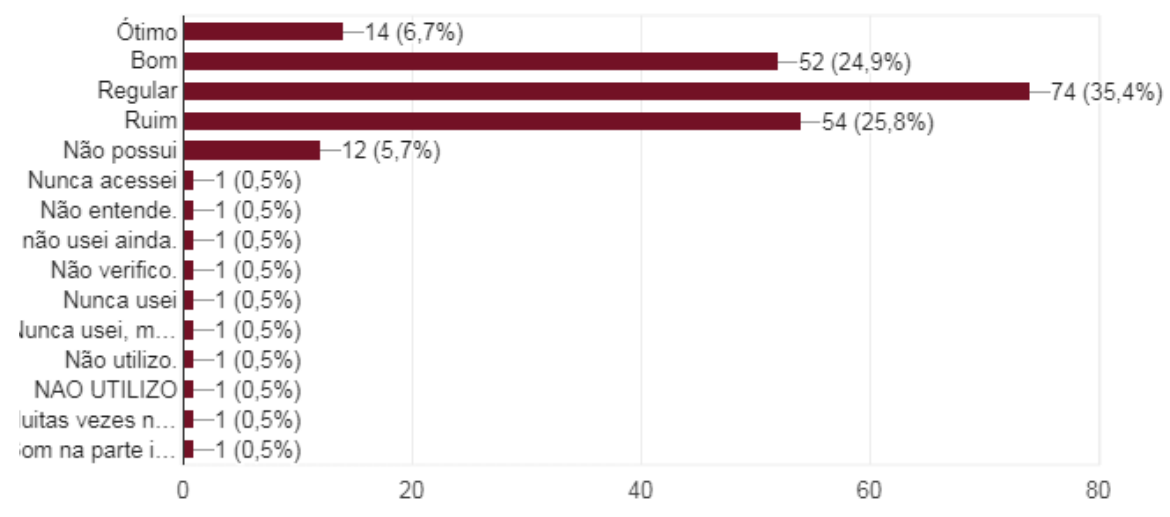

Fonte: Dados da pesquisa.

A utilização de uma boa internet também se faz necessária tanto para pesquisas dos usuários quanto para um bom funcionamento do sistema de bibliotecas web. No caso do gráfico 10, precisamos ter mais atenção para melhorar esse conteúdo nas unidades.

Em relação ao espaço físico ou à infraestrutura dos ambientes relativos às bibliotecas, os usuários apresentaram uma grande insatisfação em itens que podem e devem ser melhorados nas bibliotecas do IFBA, tais como:

- Melhorar a área de estudos coletivos para que o barulho causado pelo grupo não atrapalhe os estudos individuais;

- Melhorar a área de estudos individuais para aqueles que precisam de espaços onde possam concentrar-se melhor nos estudos;

- O silêncio precisa ser preservado no dia a dia, deixando o barulho para momento de atividades culturais ou outro tipo de atividades que movimentem a biblioteca para os grandes grupos; 
- A quantidade de computadores para pesquisa, assim como a sua manutenção constante é algo que pode melhorar em todos os campi;

- Manutenção dos banheiros próximos à área da biblioteca;

- A disponibilidade de guarda-volumes na entrada de cada biblioteca, permitindo com que os alunos possam utilizar os escaninhos para além da permanência no espaço da biblioteca.

São pequenas ações que podem melhorar muito a perspectiva do usuário em relação ao ambiente físico da biblioteca e fazer com que o espaço possa contribuir, e muito, no processo educacional.

\section{CONSIDERAÇÕES FINAIS}

A aquisição e partilha de conhecimentos passa a ser o instrumento modificador nas estruturas cognitivas do sujeito, alterando a consciência humana e produzindo conhecimento no indivíduo ao trazer benefícios para o desenvolvimento social. A informação passa a ser a condição necessária para o indivíduo adquirir conhecimento e aprender a aprender ao longo da vida.

A escola é o local onde as novas habilidades podem ser adquiridas, sendo a biblioteca o ambiente propício da nova educação, pois é o espaço onde os alunos deverão aprender a lidar com as variadas fontes e recursos de informação e, sobretudo, com a internet.

A biblioteca da escola é o espaço apropriado para fomentar programas que ensinem habilidades informacionais aos alunos com programas de competência em informação, auxiliando os mesmos na busca do conhecimento no processo da pesquisa escolar.

Os resultados alcançados apresentam a evidência de que os usuários possuem pouca familiaridade com a biblioteca. Eles não têm o hábito de frequentar a biblioteca como espaço de aprendizagem. Aqueles que frequentam a biblioteca o fazem por razões diversas, dentre muitas, utilizar o espaço apenas para encontrar amigos ou utilizar o acesso à internet para outras finalidades.

Isso pode ser considerado como um aspecto negativo para a imagem da biblioteca no IFBA, que é corroborado quando eles afirmam que frequentam pouco a biblioteca do campus, mesmo com a estrutura diferenciada dessas bibliotecas em relação a outras do mesmo município. 
Por outro lado, constatamos que os servidores também frequentam pouco o ambiente da biblioteca nos campi do IFBA, mesmo reconhecendo a sua importância no processo de ensino-aprendizagem. Os dados levantados apresentam, ainda, que os usuários buscam informações diretamente em fontes digitais, sendo esse o motivo da baixa frequência nos ambientes de aprendizagem da biblioteca.

Os dados levantados apresentam o fato de que os usuários não conhecem os passos necessários para usar a biblioteca de forma independente, desconhecem o papel do bibliotecário que, por sua vez, pouco tem feito para apresentar o seu papel de educador e mediador da informação.

Isso pode ser justificado quando percebemos que as bibliotecas do IFBA possuem um diferencial em relação a outros tipos de bibliotecas. As bibliotecas funcionam em horários ininterruptos para atendimento a alunos de diversas modalidades de ensino, comunidade interna e externa. Dessa forma, o bibliotecário, que em muitos casos está sozinho no campus, divide-se entre tarefas de cunho administrativo, atendimentos em geral, na função de catalogador, proponente de atividades culturais, e outras, não sendo, muitas vezes, possível administrar o seu tempo na função de mediador e colaborador para o desenvolvimento de atividades que desenvolvam a competência em informação em seus usuários.

Diante dessa dificuldade do bibliotecário de realizar a sua função educacional, percebe-se que os usuários continuam com a visão limitada sobre o espaço da biblioteca, não conhecendo profundamente a sua importância no contexto pedagógico. Tanto alunos quanto outros membros da comunidade interna não olham para biblioteca como espaço que deve ser aproveitado por todos, principalmente na realização da pesquisa.

A pesquisa normalmente é realizada com buscas diretamente no Google e sites similares. Por outro lado, também existe um pequeno grupo de usuários que aprenderam a utilizar outras formas de pesquisa na internet, tais como: o Portal de Periódicos da CAPES e o SciElo, ensinados, muitas vezes, pelos professores em sala de aula, fora do espaço da biblioteca e sem a interferência do bibliotecário, desconhecendo outras fontes disponíveis como as bibliotecas virtuais da instituição.

O fato é que tanto servidores quanto alunos desconhecem a função educativa do bibliotecário na figura de mediador e de educador para o desenvolvimento da competência em informação, desconsiderando-o como aquele que poderia ensiná-los a localizar a informação de forma efetiva nas fontes de informação confiáveis.

O bibliotecário poderia contribuir com a busca pela informação dos usuários em fase 
escolar, ensinando a eles o conhecimento mínimo de fontes de informação, além de ensinar a avaliar a informação encontrada nos diferentes suportes. A biblioteca do campus contribuiria com essa formação se conhecesse os seus usuários e as suas necessidades de informação, através de um estudo da comunidade, de forma que organizasse atividades de formação de usuários para o processo da pesquisa. Atualmente, percebemos que o usuário pouco conhece os serviços que a biblioteca pode lhes oferecer e buscam os auxiliares de biblioteca e, algumas vezes, o bibliotecário para informar sobre algum livro do acervo que ele não tenha localizado. Da mesma forma, o bibliotecário conhece pouco o perfil de seus usuários e quais as suas reais necessidades de informação.

Para ocorrer uma mudança nas estruturas das bibliotecas, onde a mesma possa inserir-se no cotidiano dos usuários, é necessário que haja uma colaboração entre professores e bibliotecários no sentido de se tornarem mediadores da informação no processo da pesquisa, promovendo, assim, o senso crítico nos usuários a partir da concepção construtivista, aprendendo a aprender ao longo da vida e sentindo o prazer na busca das fontes de informação.

\section{REFERÊNCIAS}

ALARCÃO, Isabel. Professores reflexivos em uma escola reflexiva. 8. ed. São Paulo: Cortez, 2011. (Coleção Questões da Nossa Época, 8).

ALMEIDA JÚNIOR. Oswaldo Francisco. Mediação da informação e múltiplas linguagens. Pesquisa Brasileira em Ciência da Informação, Brasília, v. 2, n. 1, p. 89-103, jan./dez. 2009.

AMERICAN LIBRARY ASSOCIATION. Presidential Comittee on Information Literacy: final report. Chicago, 1989. Disponível em:

<http://www.ala.org/acrl/publications/whitepapers/presidential> Acesso em: 15 set. 2012.

BAGNO, Marcos. Pesquisa na escola: o que é, como se faz. São Paulo: Edições Loyola, 1998.

BARDIN, Laurence. Análise de conteúdo. Lisboa: Persona, [1977].

BARROS, Aidil de J. P. de; LEHFELD, Neide Aparecida de S. Projeto de pesquisa: propostas metodológicas. 20. ed. Petrópolis: Vozes, 2010.

BECKER, Carolina R. F.; CHAGAS, M. As bibliotecas dos Institutos Federais de Educação, Ciência e Tecnologia - IFs: de escolares à também universitárias: a necessidade de reestruturação. In: SEMINÁRIO NACIONAL DE BIBLIOTECAS UNIVERSITÁRIAS, 22., 2012, Gramado, RS. Anais eletrônicos... Gramado: UFRGS, 2012. p. 1-9. 
BELL, J. Projeto de pesquisa: guia para pesquisadores iniciantes em educação, saúde e ciências sociais. 4. ed. São Paulo: Artmed, 2008.

BICHERI, Ana Lúcia Antunes de Oliveira. A mediação do bibliotecário na pesquisa escolar face a crescente virtualização da informação. 2008. 197 f. Dissertação (Mestrado em Ciência da informação) - Faculdade de Filosofia e Ciências, Universidade Estadual Paulista, Marília, 2008.

BOIKO, Vanessa Alessandra Thomaz; ZAMBERLAN, Maria Aparecida Trevisan. A perspectiva sócio-construtivista na psicologia e na educação: o brincar na pré-escola. Psicologia em Estudo, Maringá, v. 6, n. 1, p. 51-58, jan./jun. 2001.

BRASIL. Ministério da Ciência Tecnologia. Livro Branco: Ciência, Tecnologia e Inovação. Brasília, DF, 2002.

CAMPELO, Bernadete. Letramento informacional no Brasil: práticas educativas de bibliotecários em escolas de ensino básico. 2009. 207 f. Tese (Doutorado em Ciência da Informação) - Escola de Ciência da Informação, Universidade Federal de Minas Gerais, Belo Horizonte, 2009.

CAMPELO, Bernadete. 0 bibliotecário e pesquisa escolar. Presença Pedagógica, v. 16, n. 93, maio/jun. 2010.

CAMPELO, Bernadete. 0 movimento da competência informacional: uma perspectiva para o letramento informacional. Ciência da Informação, Brasília, v. 32, n. 3, p. 28-37, set./dez. 2003.

CAREGNATO, Sônia Elisa. O desenvolvimento de habilidades informacionais: o papel das bibliotecas universitárias no contexto da informação digital em rede. Revista de Biblioteconomia \& Comunicação, Porto Alegre, v. 8, p. 47-55, jan./dez. 2000.

CARVALHO SILVA, J. L.; SILVA, A. S. R. A mediação da informação como prática pedagógica no contexto da biblioteca escolar: algumas considerações. Biblioteca Escolar em Revista, Ribeirão Preto, v. 1, n. 2, p. 1-30, 2012.

COELHO, Marlene Morbeck. Competência informacional no ambiente de trabalho: percepção do bibliotecário de órgão público. 2008. 240 f. Dissertação (Mestrado em Ciência da informação) - Instituto de Ciência da Informação, Universidade Federal da Bahia, Salvador, 2008.

CUNHA, Murilo Bastos da. Metodologias para estudo dos usuários de informação científica e tecnológica. Revista de Biblioteconomia, Brasília, v. 10, n. 2, p. 5-19, jul./dez. 1982.

DEMO, Pedro. Educar pela pesquisa. 4. ed. Campinas, SP: Autores associados, 1996.

FERREIRA, Jairo. "Sociedade informática" e educação. In: CHIAPPINI, Ligia (Coord.). Outras linguagens na escola: publicidade, cinema e TV, rádio, jogos, informática. 4. ed. São Paulo: Cortez, 2004. (Coleção Aprender e Ensinar com Textos, 6). 
79 | Silva; Lima | Estudo de usuários para o desenvolvimento das atividades nas bibliotecas do IFBA

GIL, Antonio Carlos. Como elaborar projetos de pesquisas. 5. ed. São Paulo: Atlas, 2010.

GOLDENBERG, Mirian. A arte de pesquisar: como fazer pesquisa qualitativa em Ciências Sociais. 12. ed. Rio de Janeiro: Record, 2011.

KUHLTHAU, Carol C. Como orientar a pesquisa escolar: estratégias para o processo de aprendizagem. Trad. Bernadete Campelo. Belo Horizonte: Autêntica, 2010.

KUHLTHAU, Carol C. Inside the search process: information seeking from the user's perspective. Journal of the American Society for Information Science, v. 42, n. 5, p. 361371, 1991.

KUHLTHAU, Carol C. O papel da biblioteca escolar no processo de aprendizagem. In: VIANNA, M. M.; CAMPELO, B.; MOURA, V.H.V. (Org.). Biblioteca escolar: espaço de ação pedagógica. Belo Horizonte: EB/UFMG, 1999. p. 9-14. Seminário promovido pela Escola de Biblioteconomia da Universidade Federal de Minas Gerais, 1998.

LAU, Jesús. Diretrizes sobre desenvolvimento de habilidades em informação para a aprendizagem permanente. Veracruz, MX: IFLA, 2007. Tradução de Regina Célia Baptista Belluzzo, 2008.

LE COADIC, Yves-François. A Ciência da Informação. Trad. Maria Yêda F. S. de F. Gomes. 2. ed. Brasília, DF: Briquet de Lemos/Livros, 2004.

PACHECO, Eliezer. Os Institutos Federais: uma revolução na educação profissional e tecnológica. Natal: IFRN, 2010.

PONTES JÚNIOR, João de; TÁLAMO, Maria de Fátima G. M. Alfabetização digital: proposição de parâmetros metodológicos em competência informacional. Informação \& Sociedade: Estudos, João Pessoa, v. 19, n. 2, p. 81-98, maio/ago. 2009.

SANCHES, Gisele A. Ribeiro; RIO, Siomar Ferreira do. Mediação da informação no fazer bibliotecário no âmbito das ações culturais. InCID: Revista de Ciência da Informação e Documentação, Ribeirão Preto, v. 1, n. 2, p. 103-121, jul./dez. 2010.

SILVA, Andréia S. R.; NEVES, Dulce Amélia B.; GOMES, Maria Yêda F. S. F. Avaliação da biblioteca escolar para o desenvolvimento de competências informacionais: a experiência da biblioteca do Instituto Federal da Bahia - Campus Camaçari. Biblioteca Escolar em Revista, Ribeirão Preto, v. 2, n. 1, p. 20-40, 2013.

TAKAHASHI, T. (Org.). Sociedade da Informação no Brasil: Livro Verde. Brasília, DF: Ministério de Ciência e Tecnologia, 2000.

UNESCO. Manifesto da Biblioteca escolar da IFLA/UNESCO. 1999. Disponível em: <http://archive.ifla.org/VII/s11/pubs/portuguese-brazil.pdf>. Acesso em: 12 jun. 2012.

VIEIRA, Maria Alexandra Nogueira. Educação na sociedade da informação: uma perspectiva crítica sobre as TIC num contexto escolar. 2005. 365 f. Dissertação (Mestrado em Educação) - Instituto de Educação e Psicologia, Universidade do Minho, Braga, 2005. 
VYGOTSKY, L. "Interaction between learning and development". In: Mind and Society. Cambridge: Harvard University Press, 1978. p. 79-91.

WERTHEIN, Jorge. A sociedade da informação e seus desafios. Ciência da Informação, Brasília, v. 29, n. 2, p. 71-77, maio/ago. 2000.

YIN, Robert K. Estudo de Caso: planejamento e métodos. 4. ed. Porto Alegre: Bookman, 2010.

\section{SOBRE AS AUTORAS}

\section{Andréia Santos Ribeiro Silva}

Bibliotecária do Instituto Federal da Bahia (IFBA). Mestra em Ciência da Informação pela Universidade Federal da Bahia (UFBA).

E-mail: asribeiro2001@gmail.com

\section{Marcia Ferreira Lima}

Graduanda em Biblioteconomia pela Universidade Federal da Bahia (UFBA).

E-mail: marcialima100@hotmail.com

Recebido em: 09/03/2018; Aceito em: 26/05/2018; Revisado em: 03/06/2018.

\section{Como citar este artigo}

SILVA, Andréia Santos Ribeiro; LIMA, Marcia Ferreira. Estudo de usuários para o desenvolvimento das atividades nas bibliotecas do Instituto Federal da Bahia. Informação em Pauta, Fortaleza, v. 3, n. 1, p. 52-80, jan./jun. 2018. 